\title{
Co-producing Progression Criteria for Feasibility Studies: A Partnership between Patient Contributors, Clinicians and Researchers
}

\author{
Hannah M. L. Young ${ }^{1,2}, *$, Samantha Goodliffe ${ }^{1,2}{ }^{(0}$, Meeta Madhani ${ }^{3}$, Kay Phelps ${ }^{4}{ }^{(}$, \\ Emma Regen ${ }^{4}\left(\mathbb{D}\right.$, Anthony Locke ${ }^{5}$, James O. Burton ${ }^{6,7}$, Sally J. Singh ${ }^{1,6,8}$, Alice C. Smith ${ }^{5,+}$ and \\ Simon Conroy $4,+$ \\ 1 Department of Respiratory Sciences, University of Leicester, Leicester LE1 7RH, UK \\ 2 John Walls Renal Unit, University Hospitals of Leicester NHS Trust, Leicester LE1 5WW, UK \\ 3 Leicester Kidney Lifestyle Haemodialysis Patient Involvement Group, University of Leicester and University \\ Hospitals of Leicester NHS Trust, Leicester LE1 5WW, UK \\ 4 Department of Health Sciences, University of Leicester, Leicester LE1 7RH, UK \\ 5 Aging Related Research Patient and Public Involvement Group, University of Leicester, Leicester LE1 7RH, \\ UK \\ 6 National Centre for Sport and Exercise Medicine, Loughborough University, Loughborough LE11 3TU, UK \\ 7 Department of Cardiovascular Science, University of Leicester, Leicester LE1 7RH, UK \\ 8 Department of Respiratory Medicine, Glenfield Hospital, University Hospitals of Leicester, \\ Leicester LE1 5WW, UK \\ * Correspondence: hannah.young@uhl-tr.nhs.uk \\ + joint senior authors.
}

Received: 14 August 2019; Accepted: 29 September 2019; Published: 6 October 2019

check for updates

\begin{abstract}
There is a lack of guidance for developing progression criteria (PC) within feasibility studies. We describe a process for co-producing PC for an ongoing feasibility study. Patient contributors, clinicians and researchers participated in discussions facilitated using the modified Nominal Group Technique (NGT). Stage one involved individual discussion groups used to develop and rank PC for aspects of the trial key to feasibility. A second stage involving representatives from each of the individual groups then discussed and ranked these PC. The highest ranking PC became the criteria used. At each stage all members were provided with a brief education session to aid understanding and decision-making. Fifty members (15 (29\%) patients, $13(25 \%)$ researchers and $24(46 \%)$ clinicians) were involved in eight initial groups, and eight (two (25\%) patients, five $(62 \%)$ clinicians, one $(13 \%)$ researcher) in one final group. PC relating to eligibility, recruitment, intervention and outcome acceptability and loss to follow-up were co-produced. Groups highlighted numerous means of adapting intervention and trial procedures should 'change' criteria be met. Modified NGT enabled the equal inclusion of patients, clinician and researcher in the co-production of PC. The structure and processes provided a transparent mechanism for setting PC that could be replicated in other feasibility studies.
\end{abstract}

Keywords: feasibility; progression criteria; co-production; patient involvement; consensus; nominal group technique

\section{Introduction}

Complex health interventions involve multiple context-dependent and inter-acting components [1,2]. Consequently, they can be challenging to evaluate and implement. Feasibility studies explore the viability of a definitive randomised controlled trial (RCT) for complex interventions [2,3]. These 
types of studies are advocated when addressing key uncertainties around the design of the trial and intervention, with the overall aim of deciding whether, and how, to proceed to a full scale RCT [3-7]. Judgement regarding this is based upon a set of 'progression criteria' that are established a priori to facilitate decision-making $[3,5,6]$.

Existing guidance has broadly identified the key areas of an RCT that require progression criteria [8]. For each criterion, the development of 'stop', 'change' and 'go' thresholds is recommended, and these are typically expressed as a percentage [9]. The 'stop' thresholds indicate when there are issues that cannot be resolved, and 'go' thresholds when there are no issues that may impede the success of a trial. The 'change' threshold allows researchers to identify where there are issues that may be remedied. Enabling modification may then render a definitive RCT viable [5,9]. A systematic process for the application of these progression criteria following the completion of a feasibility study has been outlined [1], but a recent review by Hallingberg et al [7] highlighted a lack of guidance on how to devise specific a priori progression criteria [7,9]. Given this lack of guidance progression criteria are decided on an ad hoc basis, in response to the specific focus of the research, nature of the intervention and the context in which it will be applied [10].

Patient and public involvement (PPI), defined as "research being carried out 'with' or 'by' members of the public rather than 'to', 'about' or 'for' them" [11] has been shown to improve the validity, quality and relevance of feasibility studies [12]. The active participation of patient and clinician contributors is crucial to the development of progression criteria. The feasibility of future clinical implementation is as important as the feasibility of future efficacy testing [1,7,13-15]. Thus, experience of living with a health condition, and balancing trial feasibility with future 'real-world' effectiveness need to be considered alongside trial design, the nature of the intervention studied and the characteristics of the population of interest, in order to develop meaningful progression criteria $[1,7,11]$. Typically, the task of deciding progression criteria is undertaken by trial steering committees (TSCs) $[3,9,16,17]$. The involvement of lay members and clinicians within these committees is often optional or limited to consultation [12,18-20]. The methods used for developing progression criteria, and any attempts to include the differing perspectives of patients and clinicians are also rarely described.

We aimed to develop a robust and transparent method for co-producing progression criteria for frailty, falls and the role of exercise in haemodialysis patients: a mixed-methods randomised controlled feasibility study (the FLEX-HD study), which was equally inclusive of patient contributors, clinicians and researchers. The primary aims of the FLEX-HD study (ISRCTN12840463) are: to determine whether an RCT investigating the effects of an exercise intervention is feasible in people living with frailty and receiving haemodialysis, and to identify how the intervention may be tailored to the needs of this group.

There is an increasing body of literature on involving PPI members in trial design, but relatively few that specifically explore methods to share ownership around methodological or analytical decision-making [19]. The aims of this manuscript are to: outline the process used to co-produce progression criteria for a feasibility study of a complex health intervention; to describe how patient contributors, clinicians and researchers were involved as equal partners within this process; and to illustrate the use of the process using the FLEX-HD study as an example.

\section{Materials and Methods}

\subsection{Design}

Progression criteria were developed using the Nominal Group Technique (NGT), which is a structured, systematic, transparent and inclusive method for both flexibly generating ideas, and quickly coming to consensus in a face-to-face environment [21,22]. NGT involves: asking the group members to silently come up with ideas related to the given topic of discussion; sharing them; carrying out a group discussion; and finally voting and ranking them [22,23]. These components help facilitate the 
equal participation of all group members, promoting the sharing of power and the ability for all to take a key role [14,21-23].

The method can be adapted for a range of purposes [22,24-26]. We introduced a two-stage process (Figure 1) that facilitated the inclusion of a greater number of stakeholders and allowed us to provide brief face-to-face education sessions that provided group members with sufficient background information to participate equally and allowed them to seek further clarification throughout the process if required.

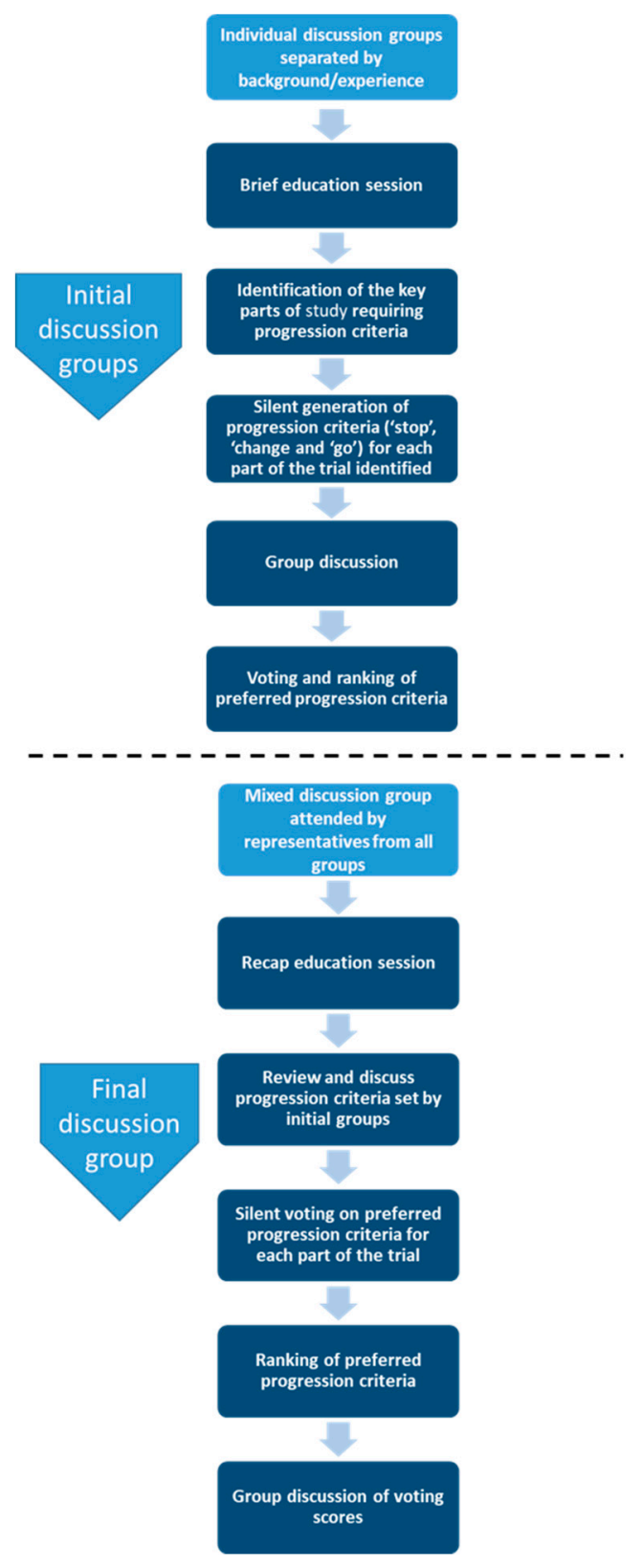

Figure 1. Adapted Nominal Group Technique Method used to establish 'stop', 'change' and go progression criteria.

\subsection{Group Members and Settings}

Potential patient contributors were identified through pre-existing patient and public involvement (PPI) groups within the University of Leicester and University Hospitals of Leicester NHS Trust, and invited to be involved based on their experience of living with frailty and receiving haemodialysis. 
Clinicians and researchers were identified via contacts within the University of Leicester, University Hospitals of Leicester NHS Trust and Lancashire Teaching Hospitals NHS Foundation Trust, and invited based upon experience related to renal disease, frailty or exercise provision, or because they represented professions most likely to be involved in delivering a definitive RCT or implementing the final intervention within clinical practice in the future.

Groups were held at the University of Leicester, Leicester General Hospital and Royal Preston Hospital at a time convenient to members. Patient contributors were reimbursed for their time and travel, in line with best practice guidance from INVOLVE, a national advisory group within the UK that aims to support active patient and public involvement in NHS, public health and social care research [27]. They lasted 60-90 minutes and were moderated by two facilitators (HY and SG), one of whom (HY) was involved in the FLEX-HD study. Moderators aimed to have minimal influence at all stages [28,29]. Group discussions were audio-recorded to provide an aide memoire to the research team. Verbal consent for the discussions to be audio-recorded was sought, but recordings were neither transcribed nor analysed [30]. The proformas used for developing the progression criteria and voting (described in Sections 2.3 and 2.4) formed the basis of the results described.

\subsection{Stage One. Initial Discussion Groups}

Plain English written materials, including an outline of the purpose and procedures used within the groups and a glossary of terms, were given to members before group attendance [31]. Prior understanding was not assumed, and all groups were provided with the same information. Greater explanations of medical terminology were provided to patient contributors and the language used adapted in consideration of possible negative connotations surrounding the term 'frailty' [32]. Large print versions of the materials were produced for visually impaired members.

Members of the initial discussion groups were grouped based upon whether they were a clinician, researcher or patient contributor to promote free discussion. Sessions began with a brief education session that provided the background information necessary to actively contribute [33]. The content of the session is outlined in Table 1. The written materials and the content of the education sessions were developed by researchers (HY, SG, KP, ER), and a PPI member with experience in health research and education (MM).

Table 1. Outline of education session content for the initial discussion groups. RCT: randomised controlled trial.

\begin{tabular}{|c|c|}
\hline Topic & Content \\
\hline Overview of RCT design & $\begin{array}{l}\text { What is an RCT? } \\
\text { What are complex interventions? } \\
\text { Challenges to RCTS of complex interventions }\end{array}$ \\
\hline Introduction to feasibility studies & What is a feasibility study? \\
\hline Introduction to progression criteria & $\begin{array}{c}\text { What are progression criteria? } \\
\text { What are they for? } \\
\text { How are progression criteria structured? } \\
\text { (introduction to 'stop/go/change' thresholds) } \\
\text { Examples of progression criteria from other studies } \\
\text { and analogies from everyday life }\end{array}$ \\
\hline Overview of the FLEX-HD study & $\begin{array}{c}\text { Aims of the study } \\
\text { Design of the study and secondary outcomes } \\
\text { Overview of the exercise intervention }\end{array}$ \\
\hline
\end{tabular}

Patient and clinician groups were also provided with an everyday analogy to facilitate their understanding of progression criteria (Figure 2) [9]. As most groups had a variety of experience of research and trials, following the education session, the key aspects of the feasibility study that typically require progression criteria were outlined by the group moderators $[5,8]$. These were eligibility 
and recruitment rates, intervention and outcome acceptability, and loss to follow-up. These terms are ill-defined within the literature [7], and therefore groups were also provided with plain English definitions of these concepts, which are outlined in Table 2. Group members were also invited to suggest any additional areas of the study where progression criteria may be indicated specifically for the FLEX-HD study.

"I would like to take my toddler on a long-haul flight to America [the definitive 'journey', used to
represent a definitive RCT], but I am concerned that the flight will be too long, difficult, and
stressful for both of us.
Before deciding if it is feasible to take her on this flight, I might see how she manages on a
shorter flight to Scotland. I might look at several key parts of this shorter journey when I am
deciding if we should go ahead with a longer flight [a progression criteria]. For example:
How does she cope during the take-off?
If she cries through most the take-off, I will decide that the take off will be too much for her
during a long haul flight [stop criteria].
- If she is settled throughout the take off, I will decide that the take off will not be a problem
during a long haul flight [go criteria].
- If she cries for part of the take-off I might look at different ways I can distract her during the
take off [change criteria]."

Figure 2. Example analogy to explain progression criteria and how 'stop', 'change' and 'go' thresholds might be applied to aid decision-making.

Table 2. Areas requiring progression criteria, and plain English explanations provided for each during the groups.

\begin{tabular}{cr}
$\begin{array}{c}\text { Aspect of the Trial Requiring } \\
\text { Progression Criteria }\end{array}$ & Plain English Explanation Provided in the Discussion Session \\
\hline Eligibility & The number of patients who can take part in the study, whether they later agree \\
to or not.
\end{tabular}

Members were then asked to suggest progression criteria for each of these aspects of the study, in turn. They were prompted to consider these using three basic questions relating to the 'stop', 'change' and 'go' criteria, which were adapted according to the specific aspect of the trial being addressed. An example is provided within Figure 3.

For each aspect of the trial, members were provided with a proforma to document their ideas for progression criteria for both 'stop' and 'go' thresholds, expressed as a percentage [22]. They were also informed that the 'change' criteria would fall between the 'stop' and 'go' thresholds and asked to document what changes could be made that might increase feasibility or acceptability. Supplementary Materials Table S1 provides a generic proforma that may be adapted for use in other studies. Members had three minutes to complete the task for each aspect of the trial. [22,23]. Typically, NGT requires participants to generate ideas for only one or two questions, but as our process required at least five aspects of the trial to be considered, the generation of ideas was time-limited [23]. 


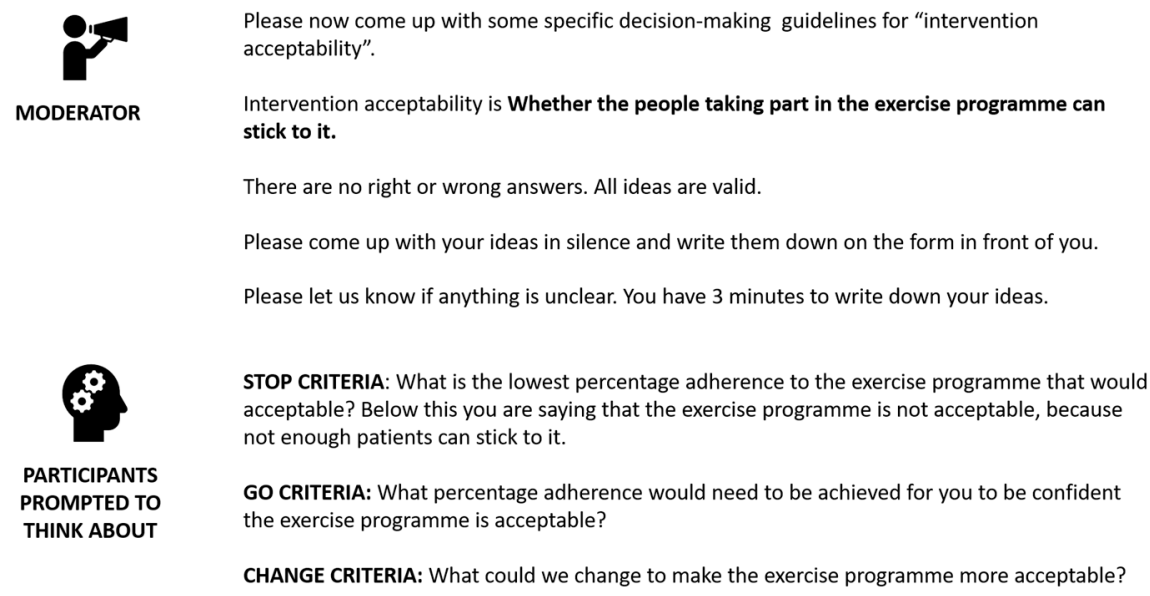

Figure 3. Example of how group members were prompt to consider the progression criteria, using intervention acceptability as an example.

No discussion was allowed, but clarification could be sought, if required [22]. All the progression criteria were collated, discussed and combined where appropriate [23]. In accordance with conventional NGT methodology, the intention was for the groups to then rank the progression criteria for each part of the trial in order of preference, to arrive at a set of final 'preferred' progression criteria [22].

\subsection{Stage Two. Final Discussion Group}

The aim of the final discussion group was to bring together contributors of all backgrounds to review the progression criteria generated by the initial groups and decide upon the final preferred progression criteria [34]. Members of the mixed final group were asked not to discuss their backgrounds to reduce potential power differentials [29]. The education session was repeated, and the anonymised progression criteria developed by the initial groups presented. Instances where multiple initial groups had come up with the same progression criteria were highlighted [25]. Fifteen minutes was allocated for group members to review and refine these until there was a condensed list. Group members were then asked to vote for their 'top three' preferred criteria from this list, using a proforma. A generic version of this proforma is included within Supplemental Materials Table S2. Voting was completed for each aspect of the trial in turn, without conferring [23]. Members awarded their preferred option the highest score (1) and continue ranking to 3, for their least preferred option. Moderators scored the votes for each potential 'stop' and 'go' criteria. Progression criteria voted in first place were awarded a score of 3 , the second a score of 2 and the last a score of 1 . The highest scoring criteria became those used in the FLEX-HD study [25]. In instances where scores were tied, further discussion and an additional vote was allowed until a preferred criterion was identified [34]. All contributors were given a written summary of the findings once all the groups were completed.

\subsection{Impact Evaluation}

The specific impact of the involvement of the patient contributors was not formally evaluated. We aimed for all members to work in partnership and singling out one group to determine the impact of their involvement felt incongruous [35]. All members were, however, invited to give verbal feedback on what worked well and what could be improved in relation to the process at the end of the discussions.

\subsection{Ethics Approval}

The UK Health Research Authority (HRA) toolkit [36] determined that the work was not considered research, as participants were not randomised, and no change to usual care or intervention was made. In addition, although the process described may be transferrable to other studies, the 'results' (i.e., the progression criteria) were specific to the FLEX-HD study, and were used solely to 
illustrate the process. Furthermore, joint guidance from the HRA and INVOLVE states that ethical approval is only required if patients are conducting research as part of the research team, or if they are involved in the study as participants [37]. In accordance with this national guidance, and following confirmation from the University of Leicester (sponsor of the FLEX-HD study), ethical approval was not required for this PPI activity.

\section{Results}

\subsection{Initial Groups}

Eight initial groups were held, involving a total of 52 members: $15(29 \%)$ patient contributors, $13(25 \%)$ researchers and $24(46 \%)$ clinicians. The characteristics of group members involved in the initial discussion groups are outlined in Table 3. The research groups included seven (54\%) research associates and six (46\%) clinical academics with a median of seven (interquartile range (IQR) 4-22) years' experience. The clinician groups included nine (36\%) physiotherapists, nine (36\%) renal nurses, five $(20 \%)$ occupational therapists and two (8\%) nephrologists with a median of 14 (3-24) years' experience. The patient contributor groups included six (40\%) people living with renal disease and nine $(60 \%)$ older people living with frailty. Across all the groups $37(71 \%)$ were female; $45(86 \%)$ were White British, six (11\%) Asian British, one (1.5\%) Black British and one (1.5\%) did not wish to state their ethnicity. Researchers were a median age of 44 (IQR 26-48) years, clinicians a median age of 38 (IQR 33-49) and patient contributors 63 (50-82) years. In total 32 (62\%) had previously been involved in research in any capacity.

Table 3. Characteristics of members of initial discussion groups. Median and IQR (interquartile range) are reported for age.

\begin{tabular}{|c|c|c|c|c|c|c|c|c|c|}
\hline \multirow[b]{2}{*}{ Group (n) } & \multirow{2}{*}{$\begin{array}{c}\text { Members } \\
\text { (n) }\end{array}$} & \multirow{2}{*}{$\begin{array}{c}\text { Age } \\
\text { (years) }\end{array}$} & \multicolumn{2}{|c|}{ Gender } & \multicolumn{4}{|c|}{ Ethnicity } & \multirow{2}{*}{$\begin{array}{l}\text { Research } \\
\text { Experience } \\
\text { (yes) }\end{array}$} \\
\hline & & & Female & Male & $\begin{array}{l}\text { White } \\
\text { British }\end{array}$ & $\begin{array}{c}\text { Asian } \\
\text { British }\end{array}$ & $\begin{array}{r}\text { Black } \\
\text { British }\end{array}$ & $\begin{array}{c}\text { Not } \\
\text { Stated }\end{array}$ & \\
\hline $\begin{array}{l}\text { Researcher } \\
\text { (2) }\end{array}$ & 13 & $\begin{array}{c}44 \\
(26-48) \\
\end{array}$ & $7(54 \%)$ & $6(46 \%)$ & $\begin{array}{c}10 \\
(77 \%) \\
\end{array}$ & $3(23 \%)$ & $0(0 \%)$ & $0(0 \%)$ & $13(100 \%)$ \\
\hline $\begin{array}{c}\text { Clinician } \\
\text { (3) }\end{array}$ & 24 & $\begin{array}{c}38 \\
(33-49)\end{array}$ & $\begin{array}{c}20 \\
(80 \%)\end{array}$ & $5(20 \%)$ & $\begin{array}{c}23 \\
(92 \%)\end{array}$ & $1(4 \%)$ & $1(4 \%)$ & $0(0 \%)$ & $7(28 \%)$ \\
\hline Patient (3) & 15 & $\begin{array}{c}63 \\
(50-82)\end{array}$ & $\begin{array}{c}10 \\
(67 \%)\end{array}$ & $5(33 \%)$ & $\begin{array}{c}12 \\
(80 \%)\end{array}$ & $2(13 \%)$ & $0(0 \%)$ & $1(7 \%)$ & $12(80 \%)$ \\
\hline
\end{tabular}

The percentage progression criteria developed for each of the aspects of the trial by each initial group are outlined in Table 4. Whilst the groups came to consensus over their preferred criteria through discussion (negating the need for the ranking task originally planned), Table 4 clearly demonstrates the wide range of progression criteria produced across the different groups. Additionally, other aspects of the trial, namely the acceptability of the randomisation procedures, intervention fidelity and incidence of adverse events and harms were identified as important by a minority of groups, reflecting the differing priorities and levels of knowledge amongst the groups. As there was uncertainty around whether these warranted progression criteria, they were not subject to voting and ranking within the final group. 
Table 4. "Stop" and "Go" progression criteria decided by individual discussion groups. Progression criteria are expressed as a percentage; blank fields indicate that the group did not set progression criteria for that aspect of the trial.

\begin{tabular}{|c|c|c|c|c|c|c|c|c|c|}
\hline \multirow{4}{*}{ Aspect of Trial } & \multicolumn{9}{|c|}{ Group } \\
\hline & \multirow{3}{*}{$\begin{array}{c}\text { Progression } \\
\text { Criteria }\end{array}$} & \multicolumn{3}{|c|}{ Patient Groups } & \multicolumn{2}{|c|}{ Researcher Groups } & \multicolumn{3}{|c|}{ Clinician Groups } \\
\hline & & $\begin{array}{l}\text { Older } \\
\text { People's } \\
\text { Group }\end{array}$ & $\begin{array}{c}\text { Renal } \\
\text { Patient } \\
\text { Group } 1\end{array}$ & $\begin{array}{c}\text { Renal } \\
\text { Patient } \\
\text { Group } 2\end{array}$ & $\begin{array}{l}\text { Age and Aging } \\
\text { Research } \\
\text { group }\end{array}$ & $\begin{array}{c}\text { Renal Exercise and } \\
\text { Rehabilitation } \\
\text { Research Group }\end{array}$ & $\begin{array}{c}\text { Renal and } \\
\text { Falls Therapist } \\
\text { Group }\end{array}$ & $\begin{array}{c}\text { Older People's } \\
\text { Therapist } \\
\text { Group }\end{array}$ & $\begin{array}{c}\text { Renal Doctors } \\
\text { and Nurses' } \\
\text { Group }\end{array}$ \\
\hline & & $\mathrm{n}=8$ & $\mathrm{n}=4$ & $\mathrm{n}=2$ & $\mathrm{n}=8$ & $\mathrm{n}=5$ & $\mathrm{n}=7$ & $n=6$ & $\mathrm{n}=12$ \\
\hline \multirow{2}{*}{ Eligibility \% } & Stop & $<50 \%$ & $<30 \%$ & $<50 \%$ & $<15 \%$ & $<20 \%$ & $<45 \%$ & $<15 \%$ & $<5 \%$ \\
\hline & Go & $>75 \%$ & $>45 \%$ & & $>25 \%$ & $>40 \%$ & $>65 \%$ & $>30 \%$ & $>20 \%$ \\
\hline \multirow{2}{*}{ Recruitment \% } & Stop & $<25 \%$ & $<35 \%$ & & $<30 \%$ & $<30 \%$ & $<20 \%$ & $<25 \%$ & $<40 \%$ \\
\hline & Go & $>80 \%$ & $>60 \%$ & $>20 \%$ & $>30 \%$ & $>50 \%$ & $>55 \%$ & $>50 \%$ & $>50 \%$ \\
\hline \multirow{2}{*}{$\begin{array}{l}\text { Intervention acceptability } \\
\text { (Adherence \%) }\end{array}$} & Stop & $<60 \%$ & $<50 \%$ & & $<25 \%$ & $<65 \%$ & $<65 \%$ & $<50 \%$ & $<50 \%$ \\
\hline & Go & $>75 \%$ & $>60 \%$ & $>40 \%$ & $>75 \%$ & $>80 \%$ & $>70 \%$ & $>75 \%$ & $>70 \%$ \\
\hline \multirow{2}{*}{$\begin{array}{l}\text { Outcome acceptability } \\
\text { (Completion \%) }\end{array}$} & Stop & & $<55 \%$ & & $<60 \%$ & $<70-80 \%$ & $<80 \%$ & $<60 \%$ & $<80 \%$ \\
\hline & Go & & $>66 \%$ & $>80 \%$ & $>40 \%$ & $>80-90 \%$ & & $>60 \%$ & $>90 \%$ \\
\hline \multirow{2}{*}{$\begin{array}{l}\text { Loss to follow up } \\
\text { (\% withdrawn or lost) }\end{array}$} & Stop & $>55 \%$ & $>60 \%$ & $>80 \%$ & $>80 \%$ & $>40 \%$ & $>50 \%$ & $>40 \%$ & $>30 \%$ \\
\hline & Go & $<25 \%$ & $<50 \%$ & $<25 \%$ & $<40 \%$ & $<25 \%$ & $<20 \%$ & $<25 \%$ & $<20 \%$ \\
\hline
\end{tabular}




\subsection{Characteristics of Final Groups}

The final joint discussion group involved 8 members: two (25\%) patient contributors, one (13\%) nephrologist, one $(13 \%)$ researcher, two $(25 \%)$ physiotherapists and two $(25 \%)$ occupational therapists. Four $(50 \%)$ were female, five (63\%) were White British and three (38\%) Asian British, with a median age of 45 (IQR 29-64) years. Six (80\%) members had been involved in an initial group and four (50\%) had previously been involved in research in any capacity.

\subsection{Ranking of Progression Criteria}

Table 5 outlines the scores given to each of the condensed progression criteria following the voting task. All the criteria ranked in first place received 67 to $100 \%$ of the votes.

Table 5. Scores and ranking of condensed progression criteria. Progression criteria are expressed as a percentage. A maximum score of 24 was possible during the voting task.

\begin{tabular}{|c|c|c|c|c|c|}
\hline Aspect of Trial & Results A & or Voting & Voting Scores & Ranking & $\begin{array}{c}\text { Final Criteria If } \\
\text { Tied Ranking }\end{array}$ \\
\hline \multirow{5}{*}{ Eligibility } & \multirow{2}{*}{ Stop } & $<20 \%$ & 22 & 1 & \\
\hline & & $<30 \%$ & 18 & 2 & \\
\hline & \multirow{3}{*}{ Go } & $>40 \%$ & 15 & $=2$ & \\
\hline & & $>45 \%$ & 15 & $=2$ & \\
\hline & & $>50 \%$ & 16 & 1 & \\
\hline \multirow{4}{*}{ Recruitment } & \multirow{3}{*}{ Stop } & $<20 \%$ & 16 & 2 & \multirow{3}{*}{$<25$} \\
\hline & & $<25 \%$ & 17 & $=1$ & \\
\hline & & $<30 \%$ & 17 & $=1$ & \\
\hline & Go & $>50 \%$ & 24 & 1 & \\
\hline \multirow{6}{*}{$\begin{array}{l}\text { Intervention acceptability } \\
\text { (adherence } \%)\end{array}$} & \multirow{3}{*}{ Stop } & $<25 \%$ & 6 & 3 & \\
\hline & & $<30 \%$ & 21 & 1 & \\
\hline & & $<50 \%$ & 16 & 2 & \\
\hline & \multirow{3}{*}{ Go } & $>70 \%$ & 18 & 1 & \\
\hline & & $>75 \%$ & 15 & 2 & \\
\hline & & $>80 \%$ & 12 & 3 & \\
\hline \multirow{4}{*}{$\begin{array}{l}\text { Outcome acceptability } \\
\text { (measure completion \%) }\end{array}$} & \multirow{2}{*}{ Stop } & $<60 \%$ & 19 & $=1$ & \multirow{2}{*}{$<70$} \\
\hline & & $<80 \%$ & 19 & $=1$ & \\
\hline & \multirow{2}{*}{ Go } & $>80 \%$ & 20 & 1 & \\
\hline & & $>90 \%$ & 15 & 2 & \\
\hline \multirow{4}{*}{ Loss to follow up } & \multirow{2}{*}{ Stop } & $>30 \%$ & 17 & $=1$ & \multirow{2}{*}{$>40$} \\
\hline & & $>50 \%$ & 17 & $=1$ & \\
\hline & \multirow{2}{*}{ Go } & $<20 \%$ & 18 & $=1$ & \multirow{2}{*}{$<20$} \\
\hline & & $<25 \%$ & 18 & $=1$ & \\
\hline
\end{tabular}

\subsection{Final Progression Criteria}

The final preferred 'stop' and 'go' progression criteria selected are presented within Figure 4. Greater flexibility was afforded to exercise adherence to allow for periods of ill-health, hospitalisation and holidays over the duration of the intervention. The thresholds for outcome measure completion were more stringent, in recognition of the high levels of data completion required to make robust conclusions about efficacy in a definitive RCT. The potential need for different 'stop' and 'go' thresholds 
for different types of outcome measures was highlighted. For example, physical function measures were time-consuming, burdensome and subject to greater influence from symptoms and illness than patient-reported measures, thus requiring more flexible thresholds for completion. Four groups stated that loss to follow-up should be assessed at interim, and one group indicated that progression criteria established for loss to follow up should be applied to both the intervention and control arms of the study separately.

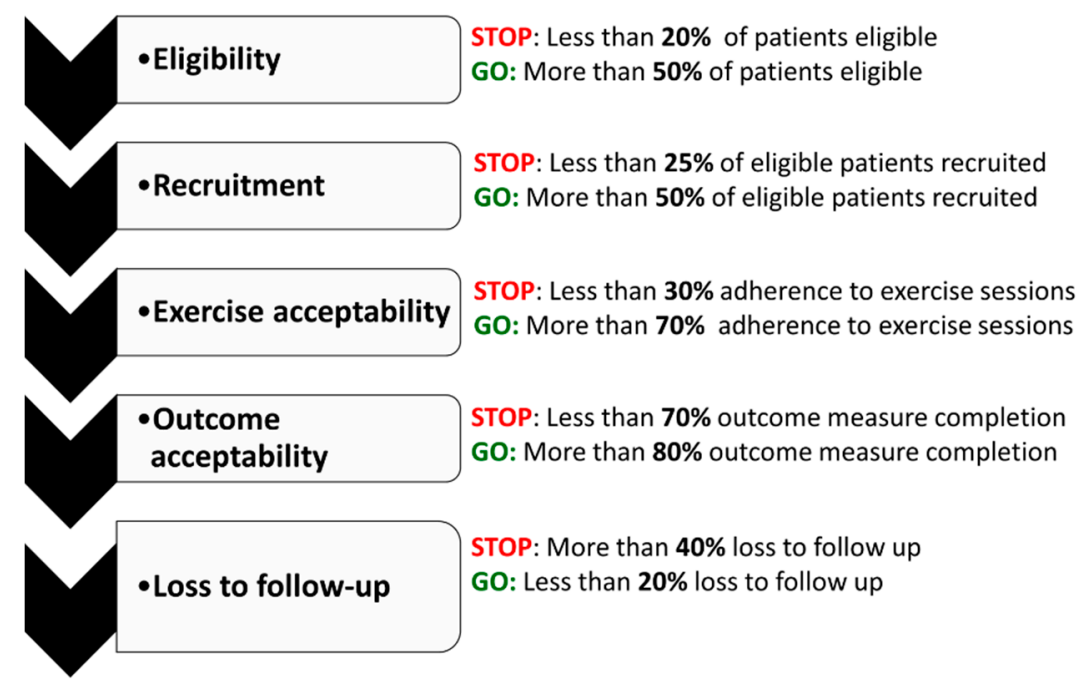

Figure 4. Final progression criteria developed for the FLEX-HD study.

\subsection{Change Criteria}

Patient contributors, clinicians and researchers across groups identified multiple different ways that the trial and intervention could be amended, should results fall between the 'stop' and 'go' thresholds, and indicate that 'change' is required. These are summarised within Figure 5.

Thirteen (25\%) initial group members identified that eligibility rates could potentially be boosted by widening the eligibility criteria, particularly in relation to frailty levels. Regular contact with those screening for eligibility, reminding them about the study and checking that screening was being completed appropriately was recommended. The therapist groups recommended that eligibility criteria for the exercise intervention be revisited should the design and delivery of the programme change significantly. For example, some participants who might not be eligible to exercise at home unsupervised may be able to exercise safely within a supervised environment, and the eligibility criteria should reflect this difference.

All groups indicated that the intervention would be the primary area of the trial to review should strategies to boost recruitment be required. Simplifying the intervention by reducing the number of visits required, the length of the intervention and making it enjoyable to participate was important.

The approach taken during recruitment was also an area highlighted for review. Explaining the study face-to-face and, where possible, exploring potential individual barriers to participation during the recruitment process was felt to be especially relevant in a population of older people living with frailty, whose participation may be limited by external constraints such as reliance upon packages of care and family assistance. By organising the trial procedures around these considerations, groups felt that more people may be encouraged to participate. When discussing the study, all groups also indicated that highlighting the potential benefits for the individual was important. 


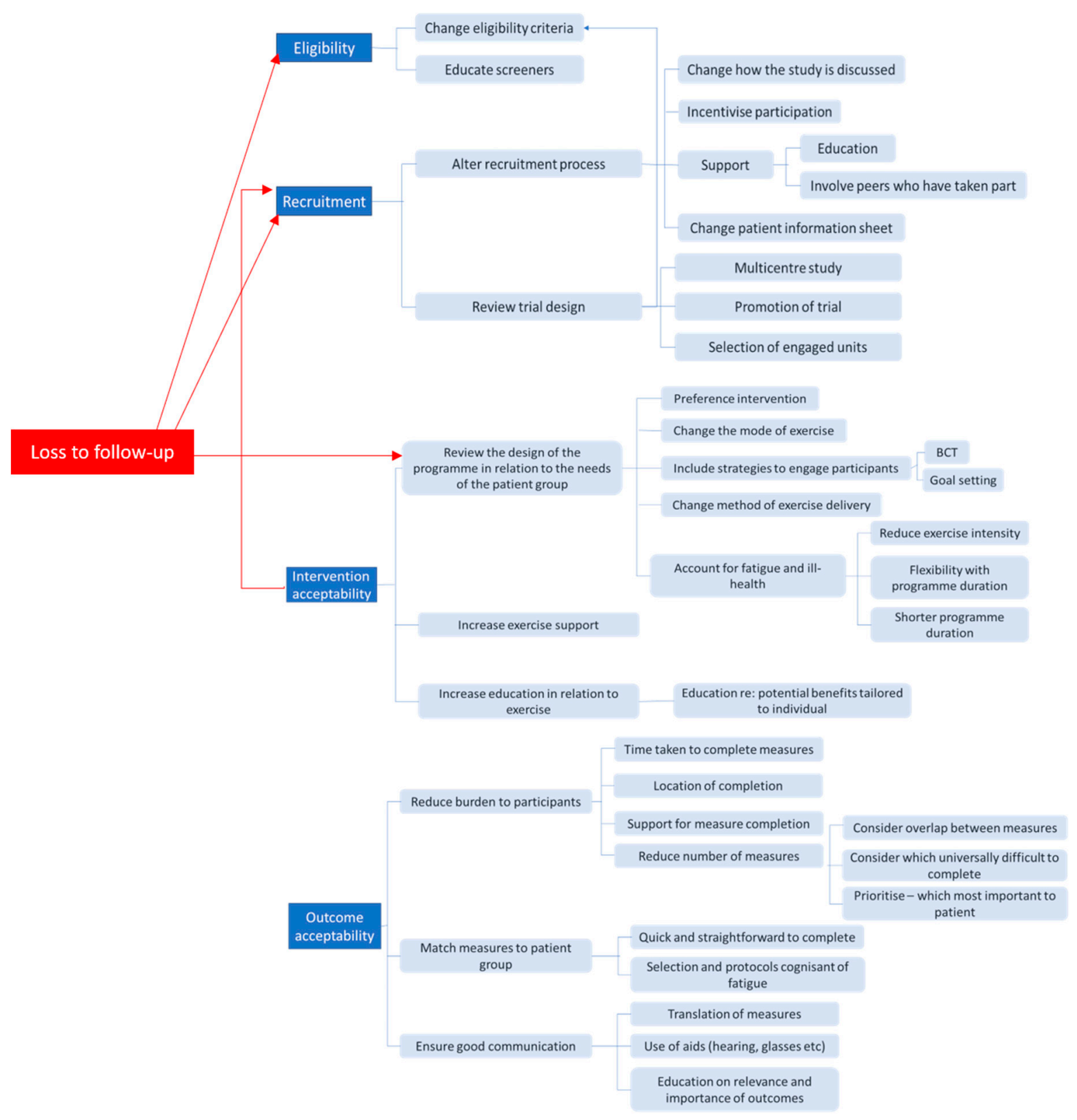

Figure 5. Suggestions for amendments to the trial and intervention should thresholds for 'change' criteria be met; BCT: Behaviour change techniques.

Involving the family in the recruitment process and enlisting the support of patient advocates and peers who had taken part in the study and giving potential participants the chance to observe the types of exercise they may be asked to participate in was also identified as important across all groups. Patient groups suggested the use of an overview booklet be used in lieu of a more traditional patient information sheet, with images alongside limited simple text. More detailed information could then be provided if interest in taking part is expressed.

Sixteen $(25 \%)$ of all members across all groups felt that varying the mode of exercise offered would increase participant engagement with the intervention by potentially making it more enjoyable. Fifteen (23\%) of all participants across all groups also suggested reviewing the intensity of the exercise programme in this population. Fatigue was identified as a key factor limiting exercise adherence for people living with frailty and receiving haemodialysis, and therefore all groups recommended lowering the exercise intensity, providing participants with a longer-run in period and offering interval training (where short bouts of moderate intensity are interspersed with those of lesser intensity). Increasing 
the support available from exercise professionals was also identified as important. Supplementing this practical support with regular reviews to check participant progress and including techniques to support and maintain behaviour change were also suggested.

Members postulated that reducing the number of measures used, and selecting those which were simple, quick and less intrusive but also meaningful to participants, would help to increase completion. Prioritising the measures key to the trial, conducting them at a time and location that was most convenient to the individual was also highlighted as important. Effective communication about what the measure is assessing, alongside support for outcome completion was additionally a frequently identified means of increasing outcome completion.

It was evident during discussion that several aspects of the trial were interlinked, and that changing one part might have a positive impact on another. For example, adapting the intervention might not only increase acceptability, but might also improve recruitment and retention. Finally, all group members emphasised the importance of understanding the barriers to feasibility from the perspectives of both participants and clinicians. They deemed this crucial to identifying those amendments most likely to result in successful delivery of the future definitive trial.

\subsection{Resource Implications}

The complete process took four months (including preparation time) and a total time of 9.5 hours to complete. The total running costs for the groups (refreshments, room hire, expenses and payments to some patient contributors) was $£ 975$.

\subsection{Impact and Feedback}

Group members valued being actively involved in setting progression criteria that would have a direct impact upon the FLEX-HD study; however, they found the application of abstract concepts and theoretical percentages challenging. They suggested that more time be allowed, and that members of the final discussion group be given an outline of the results from the individual groups to allow greater time for reflection prior to discussion.

\section{Discussion}

This work describes a transparent and collaborative process for developing progression criteria that are a critical part of determining whether a definitive RCT is feasible [3]. Some components were study specific, but the overall structure and process could be replicated within other feasibility studies. This represents a first step in addressing the paucity of guidance detailing how progression criteria should be developed [2,7]. A template for generating and subsequently voting on progression criteria for use in other feasibility studies is included within Supplementary Materials Tables S1 and S2.

\subsection{Involving Patients, Clinicians and Researchers Equally in the Co-Production of Progression Criteria}

The results of the initial groups highlight tensions between the priorities and perspectives amongst diverse groups of patient contributors, clinicians and researchers. Involving all stakeholders in the process recognises that what is feasible within a 'real world' clinical setting may be at odds with what is possible within a highly standardised research one $[7,10,14,38]$. These issues were considered and resolved in a transparent and equally inclusive manner, leading to the development of progression criteria that are meaningful within both settings. The inclusion of clinicians and patients was also particularly important within the context of the FLEX-HD study, as there is little prior research in a frail group in the field of renal rehabilitation to guide the development of progression criteria. As people living with frailty represent a 'seldom heard' group, who can be challenging to engage in research, their perspectives are crucial when determining feasibility [38-40] and working in collaboration facilitated a detailed understanding regarding how to adapt trial processes in a manner acceptable to this patient group, and the context in which they receive care. 
The use of co-production has been linked with the generation of multiple ideas for innovative intervention development and service improvement [41]; in keeping with this, the breadth of suggestions for amendments to the trial in the event of the 'change' thresholds being met strongly underlines the value of involving multiple stakeholders in the co-production of progression criteria. The combination of the group members' different types of knowledge and experience provided numerous innovative ways in which an RCT could be adapted to increase feasibility, which moved beyond the scope of those suggested by the research groups alone. The application of these potential solutions may inform whether or not to proceed to a definitive trial and would complement the decision-making process outlined by Bugge et al. [1]. When considering these amendments, the challenge for the study team is three-fold. Firstly, which of the suggestions are most likely to enhance feasibility? One option would be to compare the suggestions made with the views of the study participants if a mixed-methodology approach has been employed. Secondly, what (and how many) changes constitute major alterations to the trial and intervention? Numerous or major alterations may indicate that further development and feasibility testing is required [2], but to date there is no guidance on what amount of change would suggest that further testing is warranted [7]. Thirdly, the research team should consider how proposed changes might impact both scientific rigour and resource requirements, which could also influence feasibility [8]. For example, if outcome completion levels fall within the 'change' threshold, providing participants with support is one means of increasing completion rates, but may also necessitate additional researchers blinded to intervention groups to provide this without introducing bias.

\subsection{The Challenges of Co-Producing Progression Criteria}

Research literacy is a key component of co-production, because knowledge increases parity and participation $[7,18,42,43]$. Different levels of understanding were evident across all groups, and there were different levels of PPI and research participation experience amongst contributors. The ability of all these individuals to articulate their ideas and contribute within the group setting demonstrates inclusivity. However, there were some challenges to ensuring that all felt able to do this, and to focus those more experienced members away from issues less pertinent to feasibility studies (e.g., the need for statistical power). Whilst the education session offered aimed to ensure that all involved could contribute equally, this needed to be balanced with not overburdening group members or removing their lived or clinical experience from the forefront of their decision-making [11,19,44,45]. Similar challenges have been identified within research literacy training offered as part of community-based participatory research [46-48]. Evaluations of these programmes conclude that theoretical constructs may best be explained through practical examples [46]. A strength of our approach was introduction of a brief education session, which was developed with PPI members to include everyday analogies and jargon-free content to facilitate understanding [44,49,50]. Despite this, some members found it difficult to fully comprehend the abstract concept of a percentage-based progression criteria, which may, in part, be reflected in the wide range of criteria suggested in the initial groups. Visual methods of learning are an accessible and engaging way of increasing comprehension and encouraging creative thinking $[41,50,51]$. The use of simple graphical representations (e.g., pie charts using Microsoft Excel), or physical counters representing participant numbers, used during the groups, may have enhanced understanding of the impact of one progression criteria over other aspects of the trial. Members also fed back that additional time would be beneficial in future groups, and this may also have supported the use of visual representations.

\subsection{Limitations}

Whilst flexibility is a key feature of the NGT method, the modifications made may have influenced the criteria obtained. The omission of the ranking stage in the initial groups occurred iteratively and may have made it more difficult for some members to express their views. However, this process was carefully moderated and occurred in groups separated by background, minimising the potential impact. Some level of subjectivity is unavoidable in consensus methodology, and the inclusion of different 
members or additional groups may have resulted in different criteria [33,52]. The outcomes of this process are not generalisable, nor are they intended to be, as they have been specifically developed for the FLEX-HD study. Consensus methods are grounded within a pragmatic constructivist philosophy and therefore we seek to illustrate the rigour of the process used [53].

Finally, given the resource implications outlined, and the two-stage process used, the process may be challenging to incorporate into conventional TSC structures. Patient representation on TSCs is usually limited, and there is a perceived limited impact of patient representation, questioning whether the co-production of progression criteria is possible in this setting [7,12,18-20]. More recently there has been a shift towards involving patient advisory panels, comprising both 'expert' patient contributors as well as less experienced lay members, in specific tasks responsive to the needs of the trial. Wide representation is important from all stakeholders in the development of progression criteria $[20,45,54]$ and therefore the development of progression criteria might sit better with a patient advisory panel, alongside the research team and involved clinicians. The process could be streamlined, and resource implications reduced, by completing fewer initial groups, or by having only one mixed group inclusive of greater numbers complete both stages of the consensus processes in one sitting.

\section{Conclusions}

The use of modified NGT within diverse, structured discussion groups enabled the perspectives of patients, clinicians and researchers to be included in the co-production of progression criteria that reflected both trial and 'real-world' feasibility. Importantly, the process also allowed for the identification of numerous areas where the trial could be amended to increase feasibility if required. The main challenge to the process was reconciling different levels of knowledge and understanding amongst the contributors. Future groups would benefit from incorporating creative interactive and visual methods to facilitate understanding. The structure and processes used provide a transparent and flexible means of setting progression criteria that could be simplified, and replicated for use in other studies, with some adaptation to the address the specific focus of the trial required.

Supplementary Materials: The following are available online at http://www.mdpi.com/1660-4601/16/19/3756/s1. Table S1: Template for co-producing progression criteria for exploratory studies: generation of progression criteria, Table S2: Template for co-producing progression criteria for exploratory studies: voting form.

Author Contributions: Conceptualization, H.M.L.Y. and S.C.; Data curation, H.M.L.Y.; Funding acquisition, H.M.L.Y.; Investigation, H.M.L.Y. and S.G.; Methodology, H.M.L.Y., S.G., M.M., K.P., E.R., A.L. and S.C.; Project administration, H.M.L.Y.; Supervision S.C.; J.O.B., S.J.S. and A.C.S.; Writing-original draft, H.M.L.Y.; Writing-review and editing, S.G., M.M., K.P., E.R., A.L., J.O.B., S.J.S., A.C.S. and S.C.

Funding: The work was supported by the National Institute for Health Research (NIHR), Leicester Biomedical Research Centre, Collaboration for Leadership in Applied Health Research and Care East Midlands (CLAHRC EM) and the Stoneygate Trust. H.M.L.Y. and J.O.B. are supported by grants from the NIHR (DRF-2016-09-015 and CS-2013-13-014). S.J.S. is supported by the Collaboration for Leadership in Applied Health Research and Care East Midlands. The views expressed in this publication are those of the authors and not necessarily those of the NHS, the National Institute for Health Research or the Department of Health.

Acknowledgments: The authors wish to thank all those who co-produced the progression criteria, particularly Ann White, Jane Newstead, Emily Freeman and Andrew Nixon. We also wish to thank Courtney Lightfoot and Tom Wilkinson for their helpful comments during the preparation of the manuscript.

Conflicts of Interest: The authors declare no conflict of interest. The funders had no role in the design of the study; in the collection, analyses, or interpretation of data; in the writing of the manuscript; or in the decision to publish the results.

\section{References}

1. Bugge, C.; Williams, B.; Hagen, S.; Logan, J.; Glazener, C.; Pringle, S.; Sinclair, L. A process for decision-making after pilot and feasibility trials (ADePT): Development following a feasibility study of a complex intervention for pelvic organ prolapse. Trials 2013, 14, 353. [CrossRef] [PubMed]

2. Craig, P.; Dieppe, P.; MacIntyre, S.; Michie, S.; Nazareth, I.; Petticrew, M. Developing and evaluating complex interventions: The new medical research council guidance. BMJ 2008, 337, a1655. [CrossRef] [PubMed] 
3. Eldridge, S.M.; Chan, C.L.; Campbell, M.J.; Bond, C.M.; Hopewell, S.; Thabane, L.; Lancaster, G.A. CONSORT 2010 statement: Extension to randomised pilot and feasibility trials. Pilot Feasibility Study 2016, 2, 64. [CrossRef] [PubMed]

4. Lancaster, G.A.; Dodd, S.; Williamson, P.R. Design and analysis of pilot studies: Recommendations for good practice. J. Eval. Clin. Pract. 2004, 10, 307-312. [CrossRef] [PubMed]

5. Thabane, L.; Ma, J.; Chu, R.; Cheng, J.; Ismaila, A.; Rios, L.P.; Robson, R.; Thabane, M.; Giangregorio, L.; Goldsmith, C.H. A tutorial on pilot studies: The what, why and how. BMC Med. Res. Methodol. 2010, 10, 1. [CrossRef]

6. National Institute of Health Research. Feasibility and Pilot Studies. 2017. Available online: https://www.nihr.ac.uk/funding-and-support/documents/funding-for-research-studies/research-pro grammes/PGfAR/CCF-PGfAR-Feasibility-and-Pilot-studies.pdf (accessed on 8 February 2019).

7. Hallingberg, B.; Turley, R.; Segrott, J.; Wight, D.; Craig, P.; Craig, L.; Murphy, S.; Robling, M.; Simpson, A.; Moore, G. Feasibility studies to decide whether and how to proceed with full-scale evaluations of public health interventions: A systematic review of guidance. Pilot Feasibility Study 2018, 4, 104. [CrossRef]

8. Shanyinde, M.; Pickering, R.M.; Weatherall, M. Questions asked and answered in pilot and feasibility randomized controlled trials. BMC Med. Res. Methodol. 2011,11, 117. [CrossRef]

9. Avery, K.N.L.; Williamson, P.R.; Gamble, C.; Francischetto, E.O.; Metcalfe, C.; Davidson, P.; Williams, H.; Blazeby, J.M.; Blencowe, N.; Bugge, C.; et al. Informing efficient randomised controlled trials: Exploration of challenges in developing progression criteria for internal pilot studies. BMJ Open 2017, 7, e013537. [CrossRef]

10. Craig, P.; Di Ruggiero, E.; Frolich, K.L.; Mykhalovskiy, E.; White, M.; On Behalf of the Canadian Institutes of Health Research (CIHR)-National Institute for Health Research (NIHR) Context Guidance Authors Group. Taking Account of Context in Population Health Intervention Research: Guidance for Producers, Users and Funders of Research; NIHR Journals Library: Southampton, UK, 2018 April. Available online: https: //www.ncbi.nlm.nih.gov/books/NBK498645/ (accessed on 8 February 2019). [CrossRef]

11. INVOLVE. Guidance on Co-Producing a Research Project. 2018. Available online: https://www.invo.org.uk/ posttypepublication/guidance-on-co-producing-a-research-project/ (accessed on 7 February 2019).

12. Price, A.; Albarqouni, L.; Kirkpatrick, J.; Clarke, M.; Liew, S.M.; Roberts, N.; Burls, A. Patient and public involvement in the design of clinical trials: An overview of systematic reviews. J. Eval. Clin. Pract. 2018, 24, 240-253. [CrossRef]

13. Yardley, L.; Ainsworth, B.; Arden-Close, E.; Muller, I. The person-based approach to enhancing the acceptability and feasibility of interventions. Pilot Feasibility Study 2015, 1, 37. [CrossRef]

14. Barratt, H.; Campbell, M.; Moore, L.; Zwarenstein, M.; Bower, P. Randomised controlled trials of complex interventions and large-scale transformation of services. Health Serv. Deliv. Res. 2016, 4, 16.

15. O'Cathain, A.; Hoddinott, P.; Lewin, S.; Thomas, K.; Young, B.; Adamson, J.; Jansen, Y.; Mills, N.; Moore, G.; Donovan, J. Maximising the impact of qualitative research in feasibility studies for randomised controlled trials: Guidance for researchers. Pilot Feasibility Study 2015, 1, 32. [CrossRef] [PubMed]

16. MRC Clinical Trials Series. MRC Guidelines for Management of Global Health Trials Involving Clinical or Public Health Interventions. 2017. Available online: https://mrc.ukri.org/documents/pdf/guidelines-for-ma nagement-of-global-health-trials/ (accessed on 7 February 2019).

17. National Institute of Health Research. Research Governance Guidelines. 2012. Available online: https://www.nihr.ac.uk/funding-and-support/documents/funding-for-research-studies/how-to-apply/N ETSCC_Project_Oversight_Groups_Guidance.pdf (accessed on 7 February 2019).

18. Harman, N.L.; Conroy, E.J.; Lewis, S.C.; Murray, G.; Norrie, J.; Sydes, M.; Lane, J.A.; Altman, D.G.; Baigent, C.; Bliss, J.M.; et al. Exploring the role and function of trial steering committees: Results of an expert panel meeting. Trials 2015, 16, 597. [CrossRef]

19. Buck, D.; Gamble, C.; Dudley, L.; Preston, J.; Hanley, B.; Williamson, P.R.; Young, B. From plans to actions in patient and public involvement: Qualitative study of documented plans and the accounts of researchers and patients sampled from a cohort of clinical trials. BMJ Open 2014, 4, e006400. [CrossRef] [PubMed]

20. Dudley, L.; Gamble, C.; Preston, J.; Buck, D.; Hanley, B.; Williamson, P.; Young, B. What difference does patient and public involvement make and what are its pathways to impact? Qualitative study of patients and researchers from a cohort of randomised clinical trials. PLoS ONE 2015, 10, e0128817. [CrossRef] 
21. Department of Health and Human Services, Centres for Disease Control and Prevention. Gaining Consensus among Stakeholders through the Nominal Group Technique. 2006. Available online: https://www.cdc.gov/ healthyyouth/evaluation/pdf/brief7.pdf (accessed on 7 February 2019).

22. Potter, M.; Gordon, S.; Hamer, P. The nominal group technique: A useful consensus methodology in physiotherapy research. N. Z. J. Physiother. 2004, 32, 126-130.

23. McMillan, S.S.; Kelly, F.; Sav, A.; Kendall, E.; King, M.A.; Whitty, J.A.; Wheeler, A.J. Using the nominal group technique: How to analyse across multiple groups. Health Serv. Outcomes Res. 2014, 14, 92-108. [CrossRef]

24. Ospina, M.B.; Michas, M.; Deuchar, L.; Leigh, R.; Bhutani, M.; Rowe, B.H.; Marciniuk, D.; Goodridge, D.; Dechman, G.; Bourbeau, J.; et al. Development of a patient-centred, evidence-based and consensus-based discharge care bundle for patients with acute exacerbation of chronic obstructive pulmonary disease. BMJ Open Respir. Res. 2018, 5, e000265. [CrossRef]

25. Haugland, H.; Rehn, M.; Klepstad, P.; Krüger, A. Developing quality indicators for physician-staffed emergency medical services: A consensus process. Scand. J. Trauma Resusc. Emerg. Med. 2017, $25,14$. [CrossRef]

26. Rayment, J.; Lanlehin, R.; McCourt, C.; Husain, S.M. Involving seldom-heard groups in a PPI process to inform the design of a proposed trial on the use of probiotics to prevent preterm birth: A case study. Res. Involv. Engagem. 2017, 3, 11. [CrossRef]

27. INVOLVE. Policy on Payment of Fees and Expenses for Members of the Public Actively Involved with INVOLVE. 2016. Available online: https:/www.invo.org.uk/posttypepublication/involve-policy-on-paymen ts-and-expenses-for-members-of-the-public-including-involve-group-members-february-2016/olicyonp aymentoffees (accessed on 8 February 2019).

28. INVOLVE. Deliberative Public Engagement: Nine Principles. 2008. Available online: https://www.involve.or g.uk/sites/default/files/field/attachemnt/Deliberative-public-engagement-nine-principles_1.pdf (accessed on 10 February 2019).

29. McMillan, S.S.; King, M.; Tully, M.P. How to use the nominal group and delphi techniques. Int. J. Clin. Pharm. 2016, 38, 655-662. [CrossRef] [PubMed]

30. Pandya-Wood, R.; Barron, D.S.; Elliott, J. A framework for public involvement at the design stage of NHS health and social care research: Time to develop ethically conscious standards. Res. Involv. Engagem. 2017, 3, 6. [CrossRef] [PubMed]

31. INVOLVE. Jargon Buster. 2019. Available online: https://www.invo.org.uk/resource-centre/jargon-buster/ (accessed on 8 February 2019).

32. Age UK and British Geriatrics Society. Frailty: Language and Perceptions. A Report Prepared by BritainThinks on Behalf of Age UK and the British Geriatrics Society. 2015. Available online: https://www.ageuk.org.uk/documents/en-gb/for-professionals/policy/health-and-wellbeing/report_bgs_fr ailty_language_and_perceptions.pdf?dtrk=true (accessed on 10 February 2019).

33. James Lind Alliance. The James Lind Alliance guidebook. Version 8. 2018. Available online: www.jla.nihr.ac. uk/jla-guidebook/downloads/Version-8-JLA-Guidebook-for-download-from-website.pdf (accessed on 10 February 2019).

34. Gray, T.A.; Dumville, J.C.; Christie, J.; Cullum, N.A. Rapid research and implementation priority setting for wound care uncertainties. PLoS ONE 2017, 12, e0188958. [CrossRef] [PubMed]

35. Crocker, J.C.; Boylan, A.; Bostock, J.; Locock, L. Is it worth it? patient and public views on the impact of their involvement in health research and its assessment: A UK-based qualitative interview study. Health Expect. 2017, 20, 519-528. [CrossRef] [PubMed]

36. Health Research Authority. Is My Project Research? Available online: http://www.hra-decisiontools.org.uk/r esearch/ (accessed on 16 February 2019).

37. INVOLVE. Patient and Public Involvement in Research and Research Ethics Committee Review. 2016. Available online: https://www.invo.org.uk/posttypepublication/public-involvement-in-research-and-researc h-ethics-committee-review/ (accessed on 2 September 2019).

38. Heaven, A.; Brown, L.; Foster, M.; Clegg, A. Keeping it credible in cohort multiple randomised controlled trials: The community ageing research 75 (CARE 75) study model of patient and public involvement and engagement. Res. Involv. Engagem. 2016, 2, 30. [CrossRef] [PubMed] 
39. Ferrucci, L.; Guralnik, J.M.; Studenski, S.; Fried, L.P.; Cutler, G.B.; Walston, J.D. Designing randomized, controlled trials aimed at preventing or delaying functional decline and disability in frail, older persons: A consensus report. J. Am. Geriatr. Soc. 2004, 52, 625-634. [CrossRef] [PubMed]

40. Harris, R.; Dyson, E. Recruitment of frail older people to research: Lessons learnt through experience. J. Adv. Nurs. 2001, 36, 643-651. [CrossRef]

41. Clarke, D.; Jones, F.; Harris, R.; Robert, G. What outcomes are associated with developing and implementing co-produced interventions in acute healthcare settings? A rapid evidence synthesis. BMJ Open 2017, 7, e014650. [PubMed]

42. Komaie, G.; Goodman, M.; McCall, A.; McGill, G.; Patterson, C.; Hayes, C.; Thompson, V.S. Training community members in public health research: Development and implementation of a community participatory research pilot project. Health Equity 2018, 2, 282-287. [CrossRef]

43. Baines, R.L.; Regan de Bere, S. Optimizing patient and public involvement (PPI): Identifying its "essential" and "desirable" principles using a systematic review and modified delphi methodology. Health Expect. 2018, 21, 327-335. [CrossRef]

44. Isler, M.R.; Brown, A.L.; Eley, N.; Mathews, A.; Batten, K.; Rogers, R.; Powell, N.; White, C.; Underwood, R.; MacQueen, K.M. Curriculum development to increase minority research literacy for HIV prevention research: A CBPR approach. Prog. Community Health Partnersh. Res. Educ. Action 2014, 8, 511. [CrossRef] [PubMed]

45. Gamble, C.; Dudley, L.; Allam, A.; Bell, P.; Buck, D.; Goodare, H.; Hanley, B.; Preston, J.; Walker, A.; Williamson, P.R.; et al. An Evidence Base to Optimise Methods for Involving Patient and Public Contributors in Clinical Trials: A Mixed-Methods Study; NIHR Journals Library: Southampton, UK, September 2015; (Health Services and Delivery Research, No. 3.39). Available online: https://www.ncbi.nlm.nih.gov/books/NBK3160 49/doi:10.3310/hsdr03390 (accessed on 8 February 2019).

46. Coats, J.V.; Stafford, J.D.; Sanders Thompson, V.; Johnson Javois, B.; Goodman, M.S. Increasing research literacy: The community research fellows training program. J. Empir. Res. Hum. Res. Ethics 2015, 10, 3-12. [CrossRef] [PubMed]

47. Goodman, M.S.; Dias, J.J.; Stafford, J.D. Increasing research literacy in minority communities: CARES fellows training program. J. Empir. Res. Hum. Res. Ethics 2010, 5, 33-41. [CrossRef] [PubMed]

48. Lewis, D.; Yerby, L.; Tucker, M.; Foster, P.P.; Hamilton, K.C.; Fifolt, M.M.; Hites, L.; Shreves, M.K.; Page, S.B.; Bissell, K.L. Bringing community and academic scholars together to facilitate and conduct authentic community based participatory research: Project UNITED. Int. J. Environ. Res. Public Health 2016, 13, 35. [CrossRef] [PubMed]

49. Ashcroft, J.; Wykes, T.; Taylor, J.; Crowther, A.; Szmukler, G. Impact on the individual: What do patients and carers gain, lose and expect from being involved in research? J. Ment. Health 2016, 25, 28-35. [CrossRef] [PubMed]

50. Simon, M.A.; Haring, R.; Rodriguez, E.M.; González, E.; Kaur, J.S.; Kirschner, M.; Tom, L.; O’Brian, C.A.; Katz, M.L. Improving research literacy in diverse minority populations with a novel communication tool. J. Cancer Educ. 2018, 1-10. [CrossRef] [PubMed]

51. George, S.; Moran, E.; Duran, N.; Jenders, R.A. Using animation as an information tool to advance health research literacy among minority participants. In Proceedings of the AMIA Annual Symposium, Washington, DC, USA, 16-20 November 2013; p. 475.

52. James, D.; Warren-Forward, H. Research methods for formal consensus development. Nurse Res. 2015, 22, 35. [CrossRef]

53. Humphrey-Murto, S.; Varpio, L.; Gonsalves, C.; Wood, T.J. Using consensus group methods such as delphi and nominal group in medical education research. Med. Teach. 2017, 39, 14-19. [CrossRef]

54. Bagley, H.J.; Short, H.; Harman, N.L.; Hickey, H.R.; Gamble, C.L.; Woolfall, K.; Young, B.; Williamson, P.R. A patient and public involvement (PPI) toolkit for meaningful and flexible involvement in clinical trials-A work in progress. Res. Involv. Engagem. 2016, 2, 15. [CrossRef]

(C) 2019 by the authors. Licensee MDPI, Basel, Switzerland. This article is an open access article distributed under the terms and conditions of the Creative Commons Attribution (CC BY) license (http://creativecommons.org/licenses/by/4.0/). 